\title{
Study and Analysis of Process Parameters for Silicone Rubber Mold
}

\author{
Chil-Chyuan KUO*, Guan-Pu CHEN, Shi-Wei HUANG
}

\author{
Department of Mechanical Engineering, Ming Chi University of Technology \\ crossref http://dx.doi.org/10.5755/j01.ms.24.4.14852
}

Received 26 April 2016; accepted 08 July 2016

\begin{abstract}
Time and expense are two main key issues that are needed to develop a new product. Silicone rubber mold is one of the most commonly used techniques in the rapid tooling technology. As product life cycles are getting shorter, it is important to shorten product development time and costs, and rapid introduction of new products. Thus, enhancing the efficiency of making silicone rubber molds become an important research direction. The silicone rubber mold process parameters were investigated experimentally in this study. The results showed that the weight ratio of base compound and hardener 10:1 is the optimum ratio because the curing time of silicone rubber mold can be shortened significantly. In addition, $40-50{ }^{\circ} \mathrm{C}$ is the optimum range of curing temperature because of the shorter curing time of silicone rubber mold and $5 \%$ shrinkage of the inner dimensions of the silicone rubber mold.

Keywords: rapid tooling, silicone rubber mold, process parameters.
\end{abstract}

\section{INTRODUCTION}

New products must be more quickly and cheaply developed, manufactured and introduced to the market due to the pressure of global competition. The 3D printing technology $[1,2]$ has been developed for reducing the product development time and cost of manufacturing. However, the features of the prototype do not usually meet the need of the end product with the required material. Rapid tooling (RT) technologies are then developed. RT is regarded as a natural extension of RP since it is the technology that uses RP technologies and applies them to the manufacturing of tool inserts [3]. Since the importance of RT goes far beyond component performance testing, RT is regarded as an important method of reducing the cost and time in the development of a new product. Several RT technologies are commonly available in the industry now. In general, the RT is divided into indirect and direct tooling. The indirect tooling is easier to work with than conventional steel tooling because these tools are created from materials such as silicone rubber or aluminum-filled epoxy resins. RT is capable of replacing conventional steel tooling, saving the cost and time in the manufacturing process [4,5]. Among indirect tooling, silicone rubber mold is frequently used to develop new products because it owns flexible and elastic characteristics, so that parts with sophisticated geometry can be fabricated [6]. Thus, it is important to enhance the efficiency of making silicone rubber molds. In this study, the silicone rubber mold process parameters were investigated experimentally. The optimum process parameters were discussed and proposed. In addition, the curing mechanism of the silicone rubber mold was investigated.

\section{EXPERIMENTAL DETAILS}

The silicone rubber (KE-1310ST, Shin Etsu) was chosen as material for producing silicone rubber mold. The

\footnotetext{
* Corresponding author. Tel.: +886-2-29089899.

E-mail address: jacksonk@mail.mcut.edu.tw (C. Kuo)
}

precision electronic scale (AWH3, Excell) was used to measure the weights of base compound and hardener. The vacuum machine (F-600, Feiling) was used to eliminate air bubbles from the molding materials. The wax injection machine $(0660, \mathrm{~W} \& \mathrm{~W})$ was used to inject wax patterns through the silicone rubber mold. Fig. 1 shows the process layouts for fabricating a silicone rubber mold [7]. Silicone rubber was used as the elastomeric mold material. Base compound and hardener were mixed thoroughly to make silicone rubber molds. The amounts of base compound and hardener were calculated by multiplying the desired volume of the silicon rubber mold to be made by the density of silicone rubber $\left(1.07 \mathrm{~g} / \mathrm{cm}^{3}\right.$ at $\left.23^{\circ} \mathrm{C}\right)$. The silicone rubber and hardener in weight ratio of 10:1 was mixed thoroughly with a stirrer. The Shore A hardness of silicone rubber mold fabricated is about 40 .

Three issues regarding the silicone rubber mold process parameters were addressed. Effects of weight ratio of base compound and hardener on the curing time of silicone rubber mold were carried out. Effects of curing temperature on the curing time of silicone rubber mold were carried out. Effects of curing temperature on the dimensional accuracy of silicone rubber mold were carried out. Fig. 2 shows a mold for investigating the characteristics of silicone rubber, which was prepared by a precision milling machine. A stainless steel gauge block was selected as a master model to fabricate silicone rubber molds. The geometric size of the stainless steel gauge block is $80 \mathrm{~mm} \times 35 \mathrm{~mm}$ with $9 \mathrm{~mm}$ thickness. Calculating the weight of base and curing agent precisely is crucial before mixing. In order to reduce human error, a userfriendly man-machine interface was developed using Visual Basic program. A vacuum machine was employed to remove the air bubbles derived from the mixing process of base compound and hardener. After the degassing process, the pressure inside the vacuum machine was changed by breaking vacuum atmosphere. Thus, a silicone rubber mold can be fabricated without defects caused by the air bubbles derived from the mixing process. The properties of the silicone rubber mold, such as durability 
and mold life are significantly affected by the curing temperature. In order to investigate the optimum curing temperature, silicone rubber molds were placed in a convection oven (DH400, Deng Yag). To investigate the dimensional accuracies of the fabricated silicone rubber mold, molten wax was poured into the silicone rubber mold to fabricate wax patterns. The dimensions of the wax patterns were examined using a vision measuring system (Quick Vision Series 359, Mitutoyo).

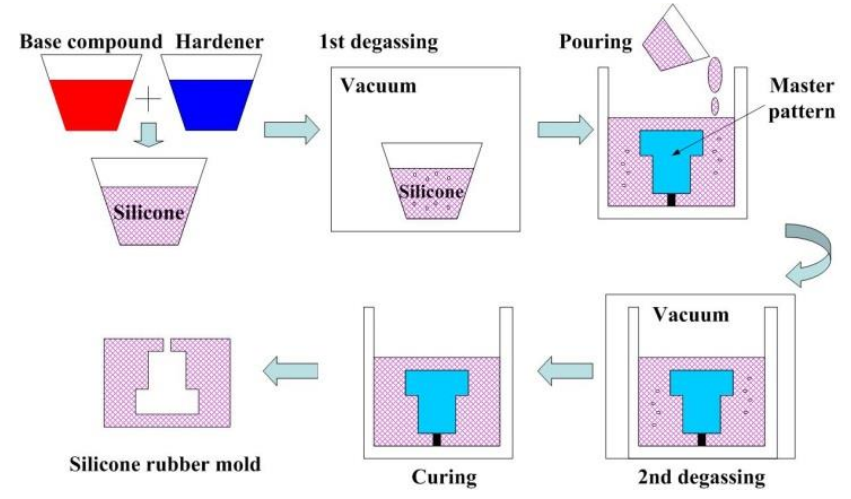

Fig. 1. Process layouts for fabricating a silicone rubber mold

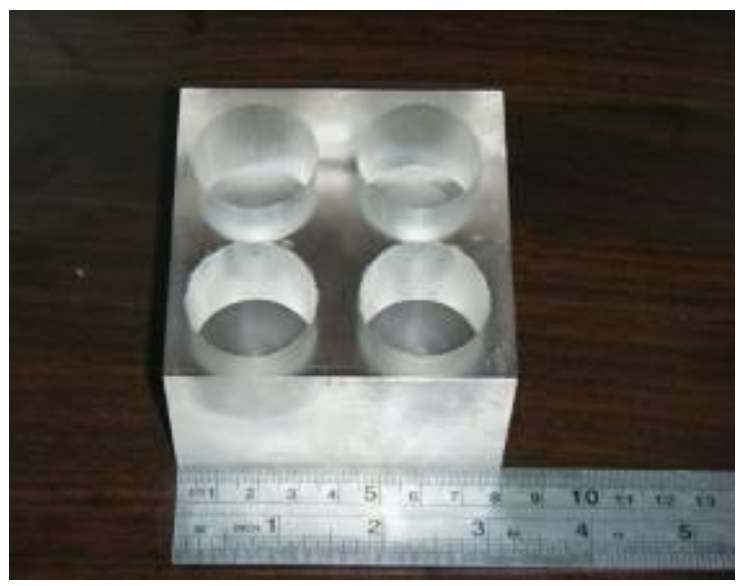

Fig. 2. Mold for investigating the characteristics of silicone rubber

\section{RESULTS AND DISCUSSION}

Traditionally, the weight ratio of base compound and hardener is 10:1 in the silicone rubber mold making process. In order to investigate the effects of the weight ratio of base compound and hardener on the curing time of silicone rubber mold [8], three different weight ratios of base compound and hardener 15:1, 10:1 and 5:1 were used for making silicone rubber molds. Table 1 shows the curing time of silicone rubber mold under three different weight ratios of base compound and hardener. As can be seen, the coefficient of variation of the curing time for different weight ratios of base compound and hardener is less than $1 \%$. The results clearly indicated that the weight ratio of base compound and hardener 10:1 is the optimum ratio because the curing time was significantly lower than base compound and hardener weight ratios of 15: 1 and 5: 1 . In addition, the curing time for the weight ratio of base compound and hardener 5:1 was not significantly shortened. This result shows that increasing the weight of hardener do not reduce the curing time of silicone rubber mold, but increasing the production cost of silicone rubber mold. Conversely, the flowability of mixed silicone rubber becomes poor when base compound and hardener weight ratios of 15:1. This indicates that it is not suitable for making silicone rubber mold with complex geometrical shapes [9].

Table 1. The curing time of silicone rubber mold under three different weight ratios of base compound and hardener

\begin{tabular}{|c|c|c|c|c|c|}
\hline $\begin{array}{l}\text { Weight ratio } \\
\text { of base } \\
\text { compound } \\
\text { and hardener }\end{array}$ & \begin{tabular}{c} 
Trial \\
\cline { 2 - 6 }
\end{tabular} & $\begin{array}{c}\text { Trial } \\
2\end{array}$ & $\begin{array}{c}\text { Trial } \\
3\end{array}$ & Mean & $\begin{array}{c}\text { The } \\
\text { coefficient } \\
\text { of } \\
\text { variation, } \%\end{array}$ \\
\hline $10: 1$ & 720 & 715 & 715 & 717 & 0.40 \\
\hline $15: 1$ & 1210 & 1205 & 1210 & 1208 & 0.24 \\
\hline $5: 1$ & 1440 & 1435 & 1435 & 1437 & 0.20 \\
\hline
\end{tabular}

In general, the curing time of silicone rubber mold can be shortened by placing the mixed silicone rubber into an oven. In general, the properties of the silicone rubber mold were significantly affected by the curing temperature. In order to investigate the effects of curing temperature on the curing time of silicone rubber mold [10], twelve different curing temperatures were used for preheating the silicone rubber mold prepared by weight ratio of base compound and hardener 10:1. Fig. 3 shows the curing time of silicone rubber mold as a function of curing temperature. As can be seen, the curing time of silicone rubber mold can be shortened from $240 \mathrm{~min}$ to $20 \mathrm{~min}$. However, the elasticity of the silicone rubber mold will reduce significantly when the curing temperature exceeds $80{ }^{\circ} \mathrm{C}$. This indicates that the optimum range for preheating the silicone rubber mold is from room temperature to $80{ }^{\circ} \mathrm{C}$.

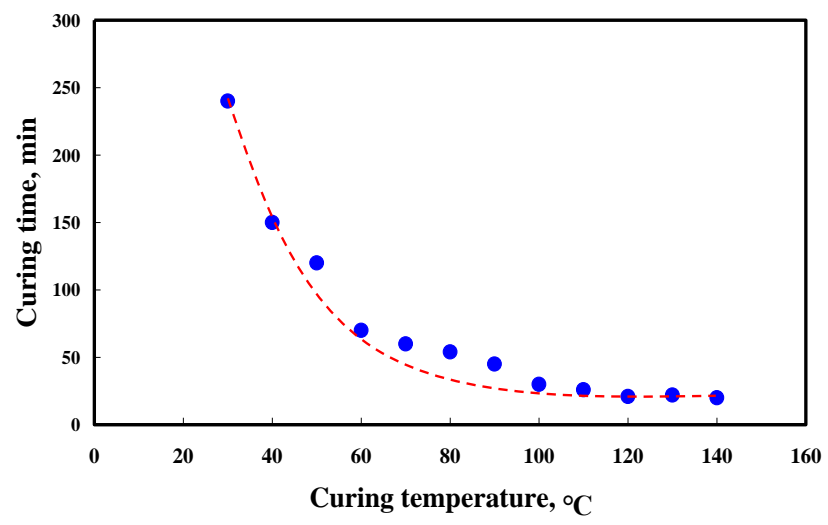

Fig. 3. The curing time of silicone rubber mold as a function of curing temperature

In order to investigate the effects of curing temperature on the dimensional accuracy of silicone rubber mold, different curing temperatures were used for preheating the silicone rubber mold prepared by weight ratio of base compound and hardener 10:1. Fig. 4 shows the silicone rubber mold of a gauge block. Fig. 5 shows the shrinkage of silicone rubber mold as a function of curing temperature. As can be seen, the shrinkage increased abruptly when the curing temperature exceeds $60^{\circ} \mathrm{C}[11]$. The shrinkage is about $5 \%$ when the curing temperature within $50{ }^{\circ} \mathrm{C}$. According to results described above, the 
optimum range of curing temperature is from room temperature to $50{ }^{\circ} \mathrm{C}$ based on the shorter curing time and less shrinkage of the silicone rubber mold when the dimensional accuracy of the finished product is crucial. Conversely, the suitable curing temperature is $80{ }^{\circ} \mathrm{C}$ when the dimensional accuracy of the finished product was not emphasized because the curing time of silicone rubber mold is the shortest. Based on the findings, this means that the optimum process parameters can enhance the efficiency of making silicone rubber molds [12, 13].

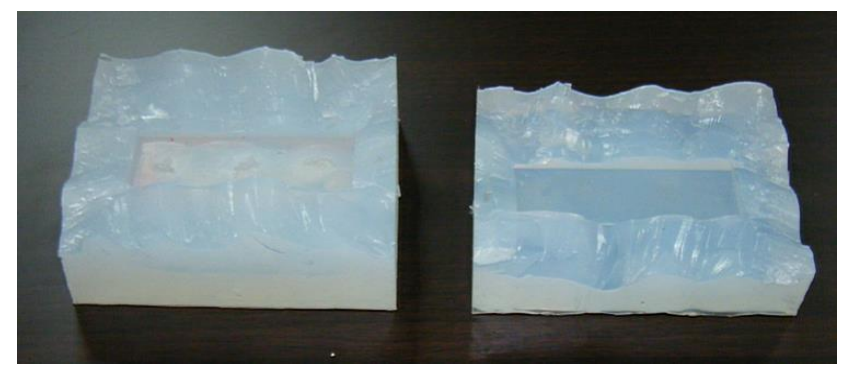

Fig. 4. Silicone rubber mold of a gauge block

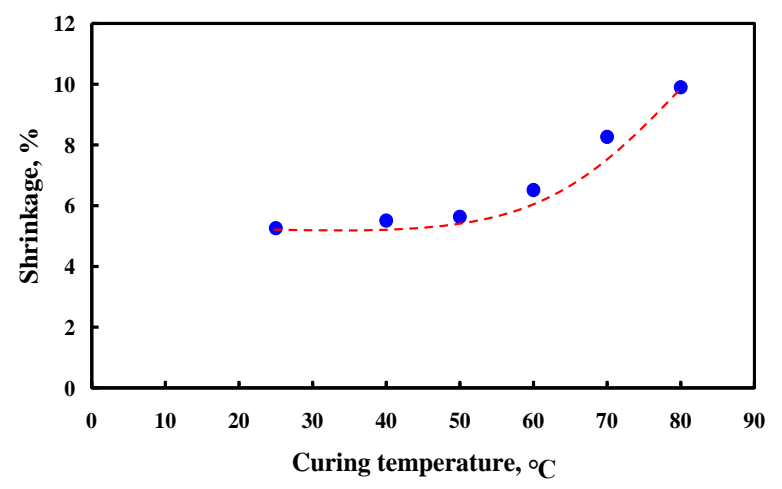

Fig. 5. Shrinkage of silicone rubber mold as a function of curing temperature

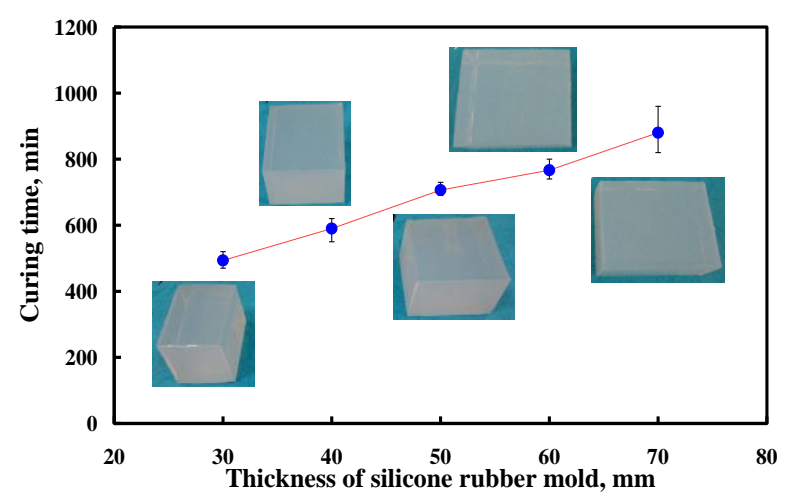

Fig. 6. The curing time as a function of different thicknesses of silicone rubber mold

Fig. 6 shows the curing time as a function of different thicknesses of silicone rubber mold. The predicted equation, $y=9.43 x+215$, can be obtained according to the curve fitting method. This means that the curing time of silicone rubber mold $(y)$ can be predicted from this equation according to the thickness of silicone rubber $(x)$. The correlation coefficient of this equation is 0.9929 .

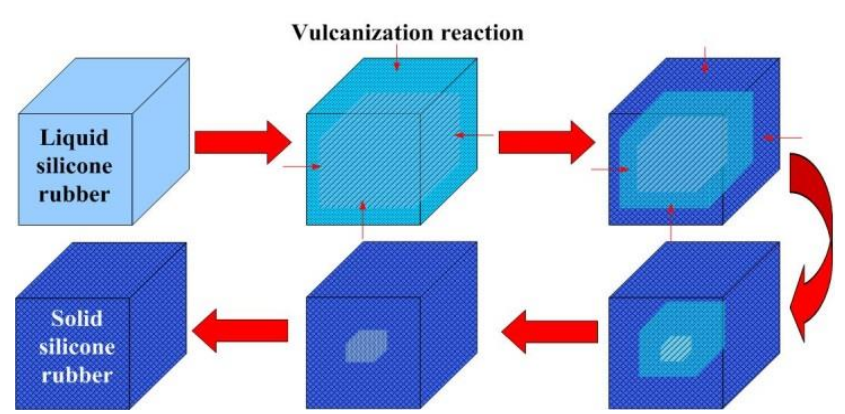

Fig. 7. Schematic illustration of the curing mechanism of silicone rubber mold

This means that this equation is a good candidate for predicting curing time of different thickness of silicone rubber molds. Fig. 7 shows the schematic illustration of the curing mechanism of silicone rubber mold. As can be seen, the outer surface of the silicone rubber mold was solidified firstly because vulcanization reaction was triggered [14] from the outer surface of the liquid silicone rubber mold. The inner liquid silicone rubber was then curing progressively.

\section{CONCLUSIONS}

Silicone rubber mold has good surface accuracy and has ability to replicate microstructures of the product. Thus, the silicone rubber mold was widely employed to develop a new product because it is fast, simple and cost-effective. The main objective of this work is to investigate process parameters for enhancing the efficiency of making silicone rubber molds. According to the experimental results discussed in this study, the main conclusions can be summarized as follows:

1. The results can accelerate the development speed in a new component development phase using silicone rubber molds.

2. The outer surface of the silicone rubber mold started to cure and the inner liquid silicone rubber was then solidified progressively.

3. The optimum weight ratio of base compound and hardener 10:1 has been verified because the curing time of silicone rubber mold can be shortened significantly.

4. The optimum range of curing temperature is from room temperature to $50{ }^{\circ} \mathrm{C}$ based on the shorter curing time and less shrinkage of the silicone rubber mold when the dimensional accuracy of the finished product need to be emphasized.

5. The suitable curing temperature is $80{ }^{\circ} \mathrm{C}$ because the curing time of silicone rubber mold is the shortest when the dimensional accuracy of the finished product do not need to be emphasized.

\section{Acknowledgements}

This work was financially supported by the Ministry of Science and Technology of Taiwan under contract nos. MOST 104-2221-E-131-026 and MOST 103-2221-E-131012 . 


\section{REFERENCES}

1. Dawoud, M., Taha, I., Ebeid, S.J. Effect of Processing Parameters and Graphite Content on the Tribological Behaviour of 3D Printed Acrylonitrile Butadiene Styrene Materialwissenschaft und Werkstofftechnik 46 (12) 2015: pp. $1185-1195$.

https://doi.org/10.1002/mawe.201500450

2. Gill, S.S., Kaplas, M. Comparative Study of 3D Printing Technologies for Rapid Casting of Aluminum Alloy Materials and Manufacturing Processes 24 (12) 2009: pp. $1405-1411$. https://doi.org/10.1080/10426910902997571

3. Palcic, I., Balazic, M., Milfelner, M., Buchmeister, B. Potential of Laser Engineered Net Shaping (LENS) Technology Materials and Manufacturing Processes 24 (7-8) 2009: pp. 750-753. https://doi.org/10.1080/10426910902809776

4. Sustarsic, B., Dolinsek, S., Jenko, M., Leskovsek, V. Microstructure and Mechanical Characteristics of DMLS Tool-Inserts Materials and Manufacturing Processes 24 (7-8) 2009: pp. 837-841 https://doi.org/10.1080/10426910902841837

5. Kuo, C.C. A Simple and Cost-Effective Method for Fabricating Epoxy-Based Composites Mold Inserts Materials and Manufacturing Processes 27 (4) 2012: pp. $383-388$. https://doi.org/10.1080/10426914.2011.551906

6. Kuo, C.C., Lin, Z.Y. Development of Bridge Tooling for Fabricating Mold Inserts of Aspheric Optical Lens Materialwissenschaft und Werkstofftechnik 42 (11) 2011: pp. 1019 - 1024 . https://doi.org/10.1002/mawe.201100819

7. Kuo, C.C., Lai, M.Y. Development of an Automatic Vacuum Degassing System and Parameters Optimization for Degassing Process Indian Journal of Engineering and Materials Sciences 18 (6) 2011: pp. 405-410.

8. Fang, W., Lai, X., Li, H., Chen, W., Zeng, X., Zhang, L., Yang, S. Effect of Urea-Containing Anti-Tracking Additive on the Tracking and Erosion Resistance of
Addition-Cure Liquid Silicone Rubber Polymer Testing 37 2014: pp. 19-27.

http://dx.doi.org/10.1016/j.polymertesting.2014.04.007

9. Chung, S., Im, Y., Kim, H., Jeong, H., Dornfeld, D.A., Evaluation of Micro-Replication Technology Using Silicone Rubber Molds and Its Applications International Journal of Machine Tools and Manufacture 43 (13) 2003: pp. $1337-1345$. http://doi.org/10.1016/S0890-6955(03)00164-0

10. Wang, X., Xia, Z., Yuan, B., Zhou, H., Li, Z., Chen, N. Effect of Curing Temperature on the Properties of Conductive Silicone Rubber Filled with Carbonyl Permalloy Powder Materials \& Design $51(287-292)$ 2013: pp. 287-292. http://dx.doi.org/10.1016/j.matdes.2013.04.007

11. Faruk, B.K.C.O., Agnelli, J.A.M., Leao, A.L., Tjong, J., Sain, M. Sisal-Glass Fiber Hybrid Biocomposite: Optimization of Injection Molding Parameters Using Taguchi Method for Reducing Shrinkage Composites Part A: Applied Science and Manufacturing 83 2016: pp. $152-159$. http://dx.doi.org/10.1016/j.compositesa.2015.10.034

12. Kuo, C.C., Lin, Z.Y. Development of Bridge Tooling for Fabricating Mold Inserts of Aspheric Optical Lens Materialwissenschaft und Werkstofftechnik 42 (11) 2015: pp. $1019-1024$. https://doi.org/10.1002/mawe.201100819

13. Kuo, C.C., Tsai, R.L. Fabrication and Application of LowPressure Wax Injection Rapid Toolings Polymers \& Polymer Composites 23 (9) 2015: pp. 647-652.

14. Mansilla, M.A., Marzocca, A.J., Macchi, C., Somoza, A. Influence of Vulcanization Temperature on the Cure Kinetics and on the Microstructural Properties in Natural Rubber/Styrene-Butadiene Rubber Blends Prepared by Solution Mixing European Polymer Journal 69 2015: pp. 50-61. http://doi.org/10.1016/j.eurpolymj.2015.05.025 